\title{
Characterization of the Nanoporous Template Using Anodic Alumina Method
}

\author{
Mau-Phon Houng, ${ }^{1}$ Wei-Lun Lu, ${ }^{1}$ Tsung-Hsin Yang, ${ }^{2}$ and Kuan-Wei Lee ${ }^{2}$ \\ ${ }^{1}$ Institute of Microelectronics, Department of Electrical Engineering, National Cheng-Kung University, Tainan 701, Taiwan \\ ${ }^{2}$ Department of Electronic Engineering, I-Shou University, Kaohsiung 840, Taiwan
}

Correspondence should be addressed to Kuan-Wei Lee; kwlee@isu.edu.tw

Received 14 April 2014; Accepted 3 June 2014; Published 30 June 2014

Academic Editor: Chien-Jung Huang

Copyright (C) 2014 Mau-Phon Houng et al. This is an open access article distributed under the Creative Commons Attribution License, which permits unrestricted use, distribution, and reproduction in any medium, provided the original work is properly cited.

Porous anodic aluminum oxide (AAO) is deposited on a $5 \mathrm{~cm} \times 5 \mathrm{~cm}$ tin-doped indium oxide (ITO)/glass substrate, and the $\mathrm{AAO} / \mathrm{ITO} /$ glass structure thus formed is used to reduce the amount of unreacted $\mathrm{Al}$ inside the AAO template, thereby reducing the transmittance of the AAO/glass structure. The enhancement of transmittance is achieved by modulating the diameter of the pores and varying the applied bias. The proposed AAO can be used at a high applied bias (up to $120 \mathrm{~V}$ ) to improve the uniformity of the current density. Following pore-widening treatment and posttreatment annealing, the morphologies and transmittance of the $\mathrm{AAO} / \mathrm{ITO} /$ glass structure were also investigated.

\section{Introduction}

Nanoporous anodic aluminum oxide (AAO) has become a commonly used material with potential applications in a wide range of areas, such as catalysis, electronics, photonics, and sensing. Owing to their regular structures and narrow size distributions of pore diameters and interpore spacings, porous alumina membranes are used in the fabrication of nanometer-scale composites [1-3]. AAO is optically transparent, electrically insulating, and mechanically robust; it is the most suitable template for nanomaterial fabrication because of its simple, intrinsically anisotropic, and self-organized porous morphology. The diameter of the pores, the pore density, and the length of the AAO template can be controlled by varying process parameters such as operating voltage, type of electrolyte acids, temperature or concentration of the electrolyte solution, and oxidation time [4-6].

The AAO method offers two main advantages. First, the fabrication of an AAO template is cost-effective and easily controlled; it yields a high aspect ratio and highly uniform pore sizes. The AAO process is better than other conventional template fabrication methods, such as atomic layer deposition [7], focused ion-beam etching [8], and scanning probe-based nanolithography. These methods are time-consuming and uneconomical and cannot be used for large-area fabrication. Additionally, the arrangement of the pores that are formed using the traditional anodization method is highly disordered. Second, the roughness of an AZO film that is deposited on an AAO nanostructure $[9,10]$ can be increased by increasing the pore diameter of the AAO film, to improve light transmittance. Based on the aforementioned advantages, the nanoporous anodic alumina has great potential for use in optoelectronic devices, including thin film solar cells and light-emitting diodes. Chu et al. [11] proposed an improved method for fabricating a transparent porous alumina nanostructure; they formed it on a glass covered tin-doped indium oxide (ITO) substrate by the anodization of a sputtered aluminum (Al) layer. The ITO film was used as a conductive layer to convert the entire $\mathrm{Al}$ to alumina. Porous materials can be used as templates in the fabrication of various nanostructures (oxides and metals) on glass, for use in photocatalysis, dye-sensitive photocells, solar energy utilization, and so on.

This work demonstrates an AAO structure and an $\mathrm{AAO} /$ ITO structure on $5 \mathrm{~cm} \times 5 \mathrm{~cm}$ glass substrates. The AAO/ITO structure is more suitable for use in optoelectronic devices 


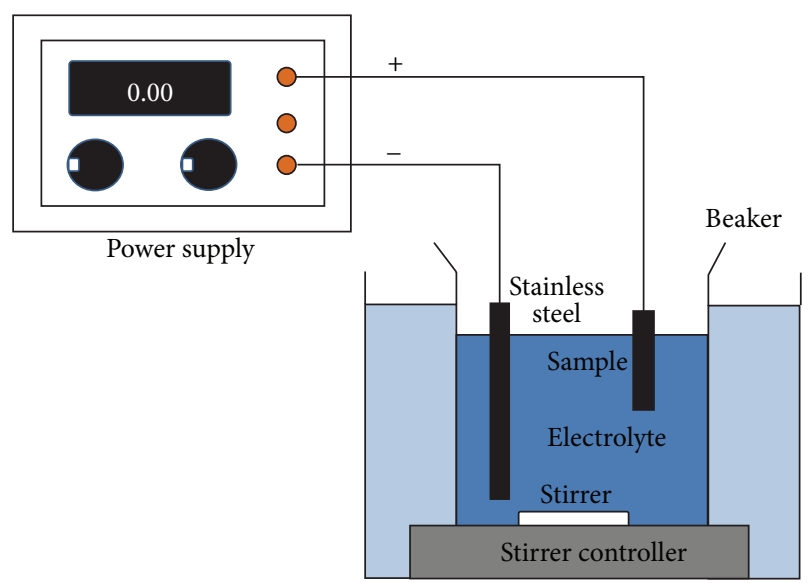

(a)

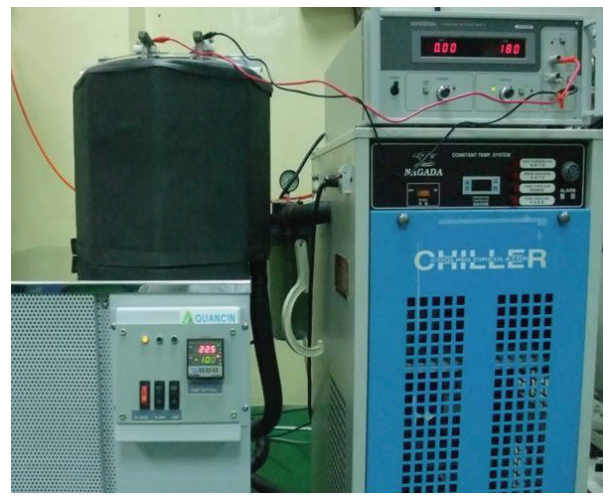

(b)

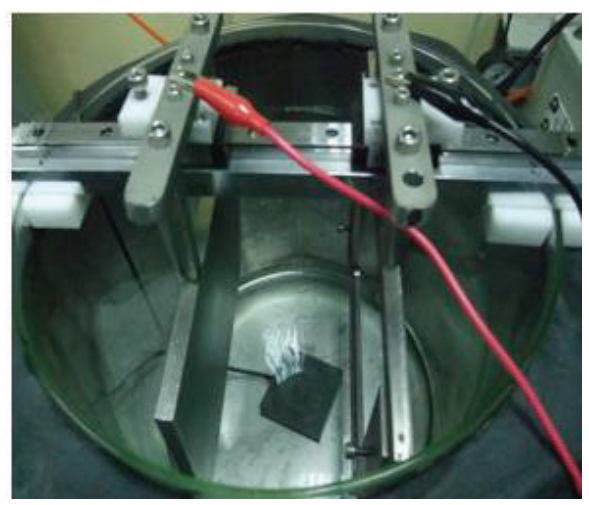

(c)

FIGURE 1: Setup for anodic oxidation: (a) experimental apparatus, (b) power supply, and (c) holder.

owing to its improved light transmittance in the nearinfrared region, based on the optical transmittance of the AAO/ITO/glass structure following pore-widening treatment and posttreatment annealing. Posttreatment annealing reduces the density of defects that arise from the chemical anodic reaction and make the surface of the anodic alumina much denser and of higher quality.

\section{Experimental}

Based on previous investigations, obtaining pores with large diameters in an AAO nanostructure is difficult if only a single $\mathrm{Al}$ film is used as the anodizing layer. Therefore, in this work, another layer is firstly deposited on the glass substrate. Two kinds of structures are formed in this experiment. One is the $\mathrm{Al} /$ glass structure that is formed by depositing an $\mathrm{Al}$ film that is deposited on a glass substrate. The other is the $\mathrm{Al} / \mathrm{ITO} /$ glass structure, which is formed by depositing an Al film on glass that has been coated with an ITO film. After the AAO and pore-widening processes, the samples with pores of various sizes in the anodic alumina structure are observed using a scanning electron microscope (SEM) (JEOL JSM-6700F). The transmittances of the AAO/glass and AAO/ITO/glass structures were measured using a UVVis-NIR spectrophotometer (Hitachi U-4100) at wavelengths from $300 \mathrm{~nm}$ to $1100 \mathrm{~nm}$. Following pore-widening treatment and posttreatment annealing, the morphology and optical transmittance of $\mathrm{AAO} /$ glass and $\mathrm{AAO} / \mathrm{ITO} /$ glass structures were obtained.

Figure 1 schematically depicts the experimental setup for anodic oxidation. A power supply and the material of the cathode are required. However, the cathode does not participate in the oxidation process; therefore, a stable material that does not easily react is required. In this work, the cathode is made of stainless steel; the anode is the sample. The sample is placed vertically in the electrolyte such that it faces the stainless steel cathode. A beaker is utilized as a holder in the anodic oxidation experiment and its use ensures that electric field is uniform. The electrolyte is $0.3 \mathrm{M}$ phosphoric acid $\left(\mathrm{H}_{3} \mathrm{PO}_{4}\right)$. A stirrer is placed in a beaker to ensure uniformity of concentration of the electrolyte during the reaction process. The beaker is put inside a cooling system, which is controlled by a bath circulator at a constant temperature. Figure 2 shows the procedure for fabricating the AAO template, which was utilized to produce the orderly array of pores.

The first step is the use of acetone solvent to remove organic contamination from the glass substrate ultrasonically for 5 minutes. The second step is the use of methanol as a solvent to remove acetone residue from the glass substrate 


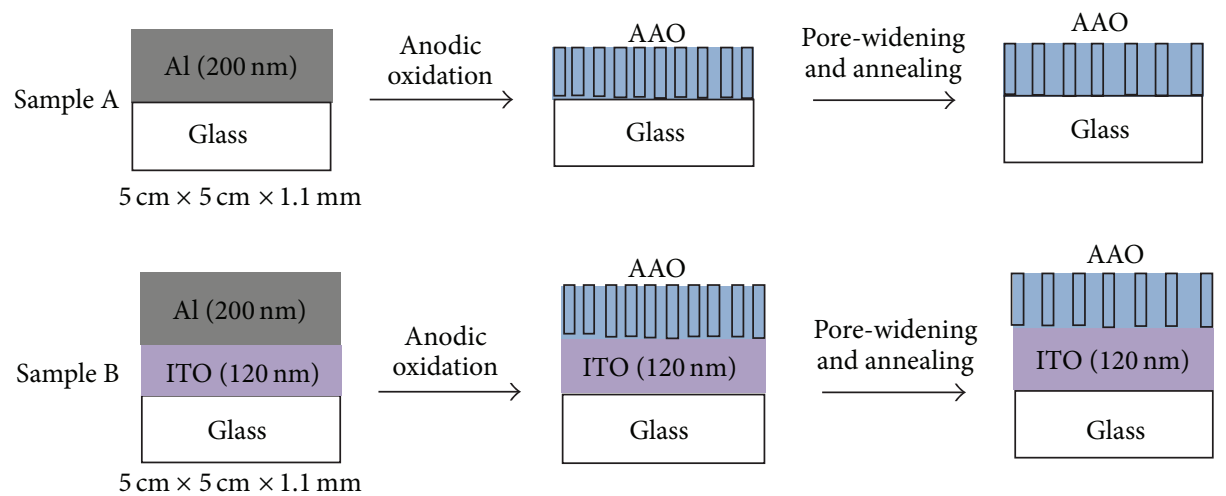

Figure 2: AAO process on $5 \mathrm{~cm} \times 5 \mathrm{~cm}$ glass substrate and $5 \mathrm{~cm} \times 5 \mathrm{~cm} \mathrm{ITO/glass} \mathrm{substrate.}$

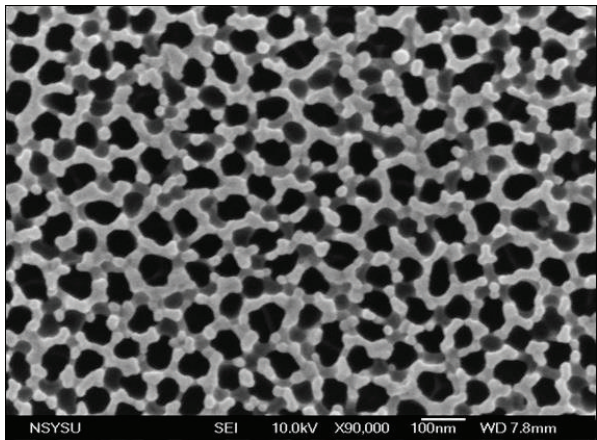

(a)

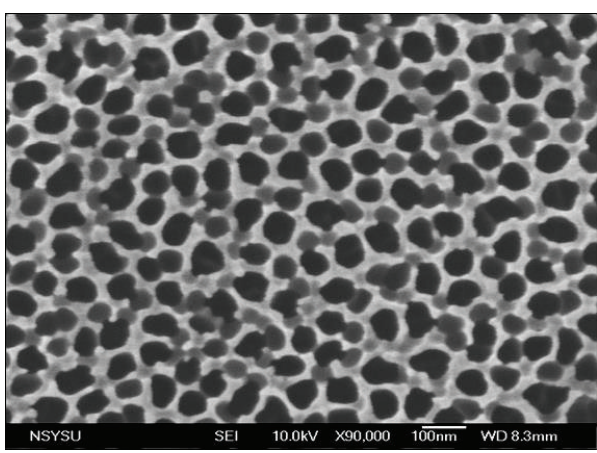

(c)

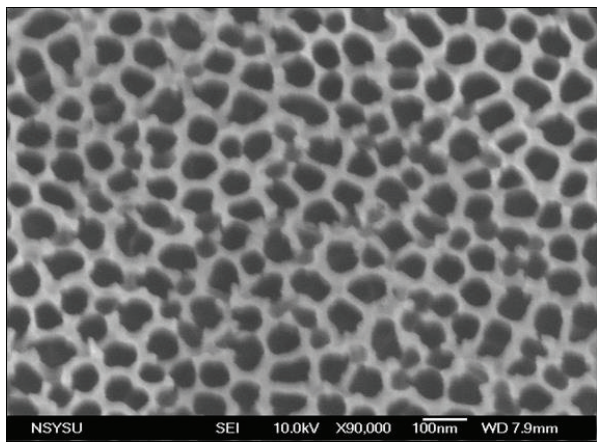

(e)

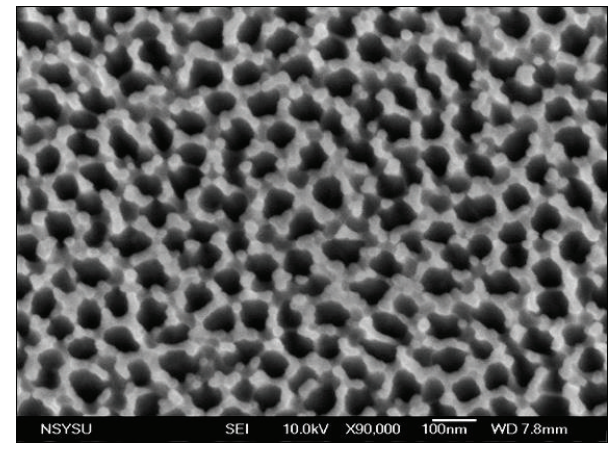

(b)

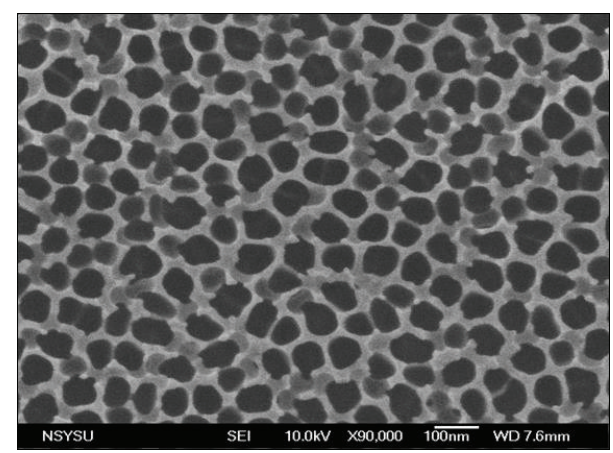

(d)

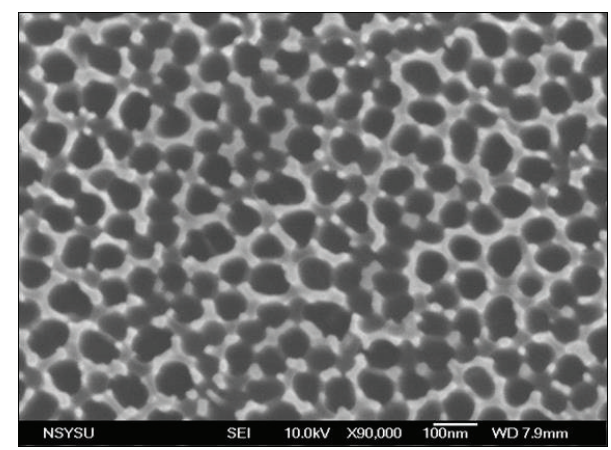

(f)

FIGURE 3: SEM micrographs of AAO films (sample A) at various concentrations: (a) $0.1 \mathrm{M}$, (b) $0.2 \mathrm{M}$, (c) $0.3 \mathrm{M}$, (d) $0.4 \mathrm{M}$, (e) $0.5 \mathrm{M}$, and (f) $0.6 \mathrm{M}$. After anodic oxidation, pore-widening treatment was performed in $6 \mathrm{wt} \% \mathrm{H}_{3} \mathrm{PO}_{4}$ at $30^{\circ} \mathrm{C}$. 


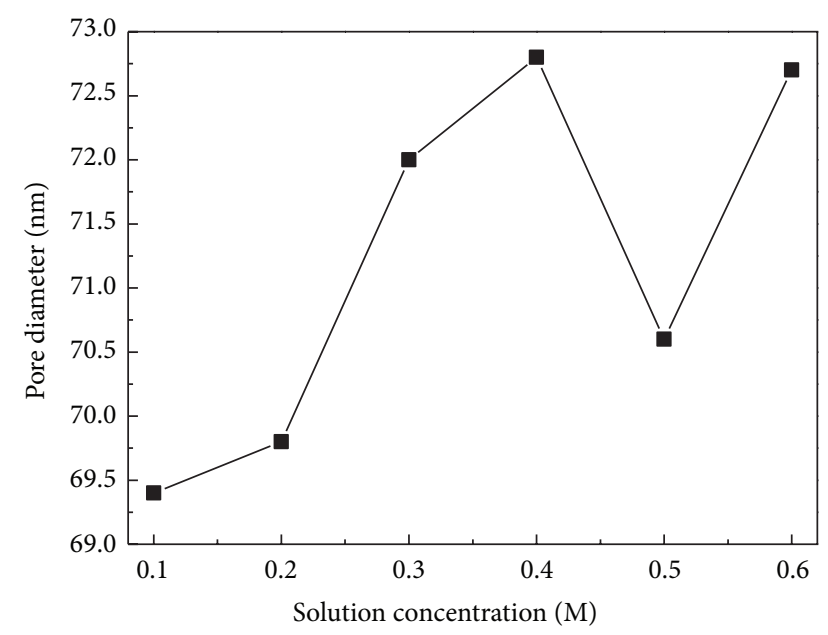

FIGURE 4: Diameter of pores in AAO/glass structures anodized using various concentrations.

ultrasonically for 5 minutes. The third step is the use of DI water to remove residual methanol from the glass substrates ultrasonically for 10 minutes, followed by drying using nitrogen gas.

A $200 \mathrm{~nm}$ thick $\mathrm{Al}$ film was deposited on $5 \mathrm{~cm} \times 5 \mathrm{~cm}$ glass substrates to form sample A and on $5 \mathrm{~cm} \times 5 \mathrm{~cm}$ glass substrates that were coated with an ITO film (ITO thickness $\cong$ $120 \mathrm{~nm}$, ITO resistance $\cong 15 \Omega / \square)$ to form sample B; a DC magnetron sputtering system with a power density of $3 \mathrm{~kW}$ was used. Next, sample A with the Al/glass structure were anodized using various parameters- $-0.1-0.6 \mathrm{M} \mathrm{H}_{3} \mathrm{PO}_{4}$, 5-35 ${ }^{\circ} \mathrm{C}$ and $20-60 \mathrm{~V}$; sample $\mathrm{B}$ with the $\mathrm{Al} / \mathrm{ITO} /$ glass structure were anodized in $0.3 \mathrm{M} \mathrm{H}_{3} \mathrm{PO}_{4}$ at $3^{\circ} \mathrm{C}$ at $20-120 \mathrm{~V}$. A porous alumina structure was then formed on the glass substrate. Following anodic oxidation, samples $\mathrm{A}$ and $\mathrm{B}$ were immersed in a $6 \mathrm{wt} \% \mathrm{H}_{3} \mathrm{PO}_{4}$ solution at $30^{\circ} \mathrm{C}$ with lower anodic oxidation voltages $(20-60 \mathrm{~V})$; sample $\mathrm{B}$ were immersed in a $6 \mathrm{wt} \% \mathrm{H}_{3} \mathrm{PO}_{4}$ solution at $45^{\circ} \mathrm{C}$ with higher anodic oxidation voltages $(80-120 \mathrm{~V})$. Etching with $\mathrm{H}_{3} \mathrm{PO}_{4}$ enlarged the pores and removed the barrier layer. After the pores had been widened, samples A and B were annealed in the ambient atmosphere at $520^{\circ} \mathrm{C}$ for 9 min to make the residual $\mathrm{Al}$ to convert them to alumina.

\section{Results and Discussion}

\subsection{Fabricating AAO under Various Anodization Conditions}

3.1.1. Concentration of Electrolyte. The rate of pore growth is generally related to the concentration of hydrogen ions. The reaction rate increases linearly with concentration, accelerating the dissolution of the alumina film, slowing its growth rate, and reducing its hardness. According to the experience, the barrier layer and porous oxide films are not conductive. Therefore, the volume of pores becomes a higher proportion; the equivalent resistance decreases. Sample A with the $\mathrm{Al} /$ glass structure were anodized at $25^{\circ} \mathrm{C}$ at $30 \mathrm{~V}$. Figure 3 presents the SEM morphologies of AAO films at
0.1-0.6 $\mathrm{M} \mathrm{H}_{3} \mathrm{PO}_{4}$ following pore-widening treatment. The diameter of the pores slightly increased with the concentration, as shown in Figure 4; regularity of the shape of the pores also increased. In Figure 4, the pore diameter increases with the concentration of the solution from 0.1 to $0.4 \mathrm{M}$; the anodic reaction is suspected to have become saturated at a concentration of $0.4 \mathrm{M}$, before the concentration reached its final value of $0.6 \mathrm{M}$. The pore diameter that was obtained at $0.5 \mathrm{M}$ is suspected to be the deviation from measurement or inaccurate sample.

3.1.2. Reaction Temperature. The effect of reaction temperature is similar to the concentration of electrolyte in the anodic oxidation for growing alumina films. Therefore, when the $\mathrm{Al}$ is anodized, the temperature of the electrolyte must be strictly controlled; a low-temperature circulatory system is generally used to keep the temperature of the electrolyte at a fixed value, ensuring that the obtained alumina films have high quality. Under constant current conditions, the thickness of the oxide layer is proportional to the charge accumulation. The formation of oxide thickness should maintain identically, but the higher operating temperature increases the erosive rate of the alumina by the acid solution. Therefore, the pores in the alumina become large, so the equivalent resistance is reduced. Figure 5 shows the SEM top-view morphology of AAO films that were anodized using $0.3 \mathrm{M} \mathrm{H}_{3} \mathrm{PO}_{4}$ at $30 \mathrm{~V}$ at $5-35^{\circ} \mathrm{C}$ and then underwent pore-widening treatment. The diameter of the pores in the AAO films did not increase significantly with the reaction temperature, as shown in Figure 6. However, the reaction rate increased with the reaction temperature, because if the current density is too high, then thermal effect increases the temperature of the electrolyte, accelerating the dissolution of the alumina films.

3.1.3. Applied Voltage. The anodizing voltage is varied to yield pores with various diameters in the AAO template. Sample B with the Al/ITO/glass structure were anodized using $0.3 \mathrm{M} \mathrm{H}_{3} \mathrm{PO}_{4}$ at $3^{\circ} \mathrm{C}$. After the pore-widening treatment at $80-120 \mathrm{~V}$, the SEM morphologies of the AAO films were obtained, as shown in Figure 7. The average pore diameter increased from $155 \mathrm{~nm}$ to $225 \mathrm{~nm}$ as the bias voltage increased from $80 \mathrm{~V}$ to $120 \mathrm{~V}$, as plotted in Figure 8. The bias voltage significantly affected the diameter and regularity of the shape of the pores in the AAO films. Therefore, nanopore size increased with operating voltage, and pore diameter was linearly proportional to the applied voltage.

\subsection{Analysis of Optical Properties}

3.2.1. AAO/Glass Structure. In fact, the anodic oxidation reaction proceeded strongly at the interface between acid solution and $\mathrm{Al}$ film resulting in the beginning of oxidation, and the newly formed porous alumina cut off the conductive path to the contact point, leaving a small amount of unreacted $\mathrm{Al}$ as isolated islands inside the sample [12]. The rate of conversion of $\mathrm{Al}$ to alumina is proportional to the bias voltage, so the amount of $\mathrm{Al}$ converted to alumina also increases with the bias voltage. However, once the anodic 


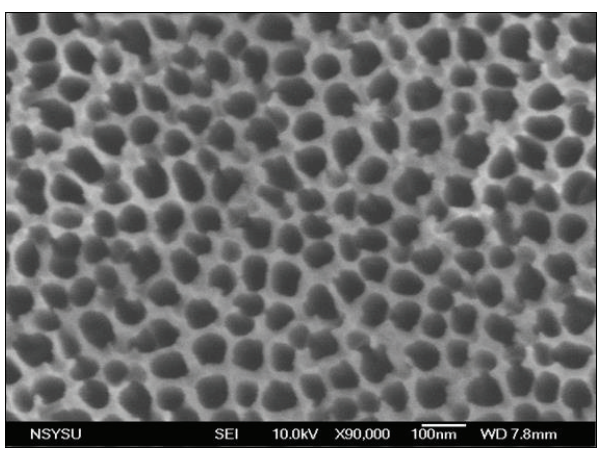

(a)

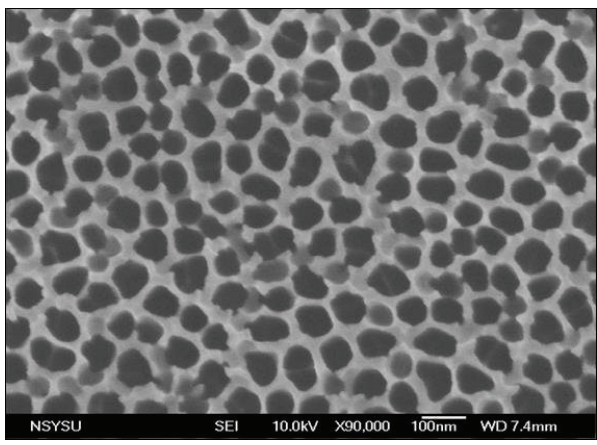

(c)

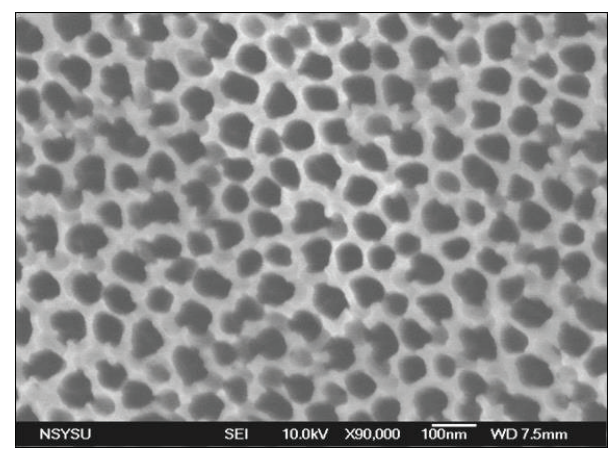

(b)

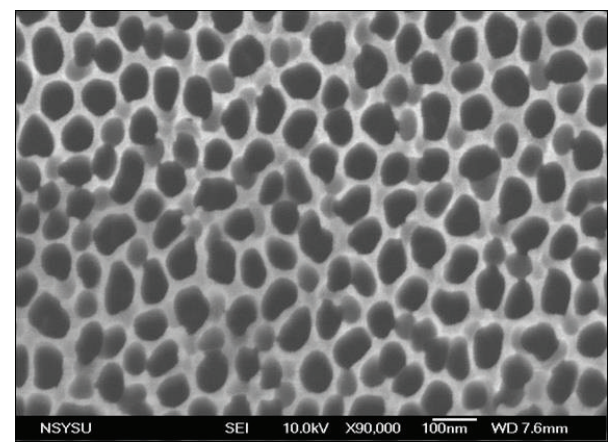

(d)

Figure 5: SEM micrographs of AAO films (sample A) at various reaction temperatures: (a) $5^{\circ} \mathrm{C}$, (b) $15^{\circ} \mathrm{C}$, (c) $25^{\circ} \mathrm{C}$, and (d) $35^{\circ} \mathrm{C}$. Following anodic oxidation, pore-widening treatment was performed in $6 \mathrm{wt} \% \mathrm{H}_{3} \mathrm{PO}_{4}$ at $30^{\circ} \mathrm{C}$.

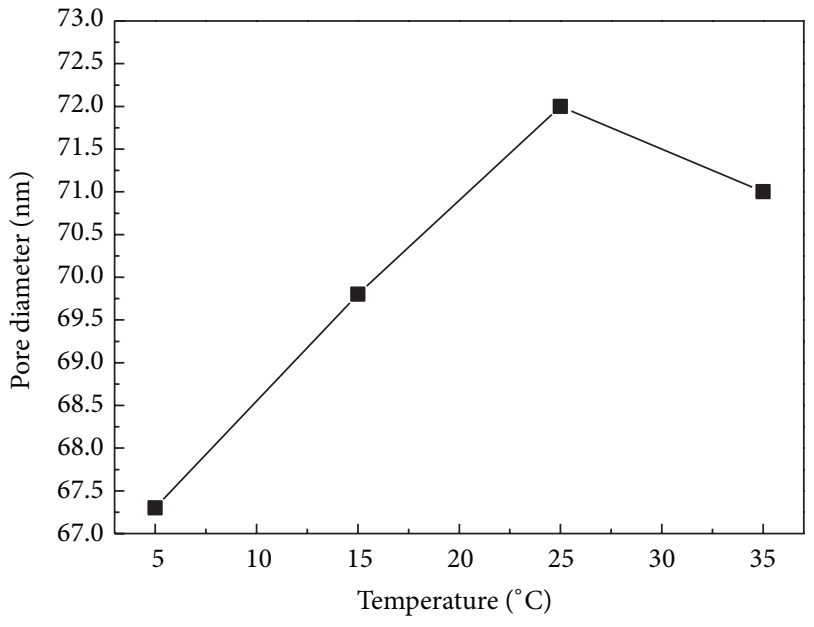

FIGURE 6: Diameter of pores in AAO/glass structures anodized at various reaction temperatures.

oxidation was stopped early, the quantity of unreacted $\mathrm{Al}$ increases. Hence, the average transmittance of AAO film decreases as the bias voltage increases.

The average transmittance of $\mathrm{AAO} /$ glass decreases from $93 \%$ to $72 \%$ as the bias voltage increases from $20 \mathrm{~V}$ to $60 \mathrm{~V}$ for wavelength from $450 \mathrm{~nm}$ to $1100 \mathrm{~nm}$ after posttreatment annealing, as shown in Figure 9. The average transmittance of the AAO film at various bias voltages increased greatly because the unreacted $\mathrm{Al}$ is converted to alumina by the posttreatment annealing [13]. Despite the fact that the transmittance of AAO is increased by the posttreatment annealing, not all of the residual $\mathrm{Al}$ can be converted to alumina. The average transmittance of the AAO film at $60 \mathrm{~V}$ is less than $75 \%$ at a wavelength of $550 \mathrm{~nm}$. Therefore, the amount of unreacted $\mathrm{Al}$ is a problem when the AAO process is performed at a high bias voltage.

3.2.2. AAO/ITO/Glass Structure. In Figure 10, the transmittance of the AAO films on the ITO conductive layers at various voltages from $20 \mathrm{~V}$ to $120 \mathrm{~V}$ after posttreatment annealing is compared with that of the as-grown ITO/glass structure. The average transmittance of the sample with the porous anodic structure at a wavelength of $550 \mathrm{~nm}$ exceeds $85 \%$ at bias voltages from $20 \mathrm{~V}$ to $120 \mathrm{~V}$ and exceeds that of the as-grown ITO/glass substrate, especially at wavelengths from $600 \mathrm{~nm}$ to $1100 \mathrm{~nm}$, because adding the ITO conductive layer to the interface between the glass and the $\mathrm{Al} \mathrm{film} \mathrm{increases}$ the duration of conversion of $\mathrm{Al}$ to alumina. The decrease in the number of free electrons that are generated by intrinsic vacancies in the as-grown ITO film is argued to inhibit the absorption of free carriers by the ITO film, so that the transmittance of the ITO film with the AAO structure is more strongly enhanced than that of the as-grown ITO film without 


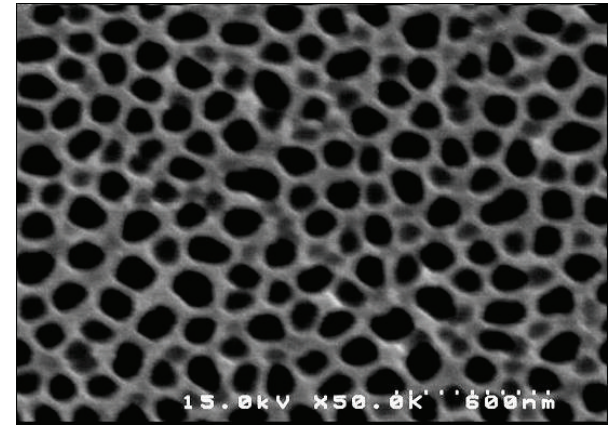

(a)

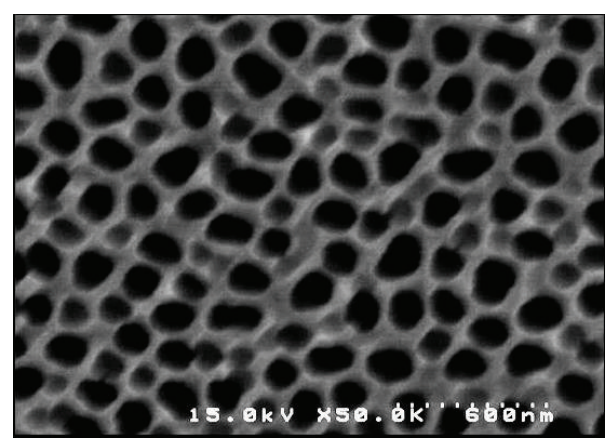

(b)

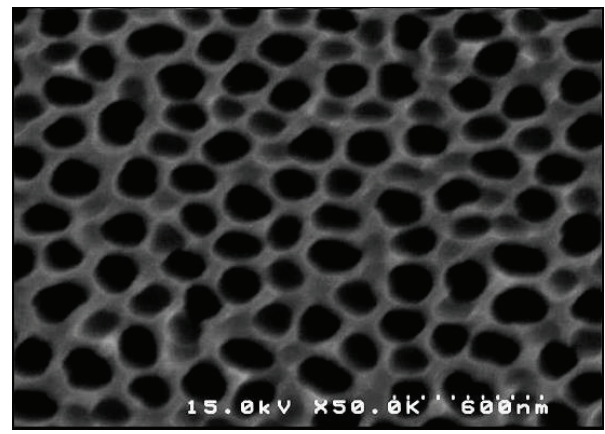

(c)

FIGURE 7: SEM micrographs of AAO films with ITO conductive layer (sample B) at various bias voltages: (a) $80 \mathrm{~V}$, (b) $100 \mathrm{~V}$, and (c) $120 \mathrm{~V}$. After anodic oxidation, pore-widening treatment was performed in $6 \mathrm{wt} \% \mathrm{H}_{3} \mathrm{PO}_{4}$ at $45^{\circ} \mathrm{C}$.

the AAO structure. Since the ITO conductive layer also reacts very strongly at the interface between the acid solution and $\mathrm{Al}$ film, the anodic oxidation stops quickly. Hence, the anodic oxidation reaction proceeds very strongly at high voltage, so the average transmittance decreases as bias voltage increases to $120 \mathrm{~V}$ at wavelengths from $600 \mathrm{~nm}$ to $1100 \mathrm{~nm}$.

The above trend is similar to that of large scale $(20 \mathrm{~cm} \times$ $20 \mathrm{~cm}$ ) AAO/ITO/glass structure [14]. Therefore, this periodic structure can serve as an optical trap in photovoltaic applications or enhance light extraction in light-emitting diodes as dielectric characteristics modulate the refractive index. Moreover, this AAO template can potentially be used for passivation in crystalline silicon solar cells owing to its native charges.

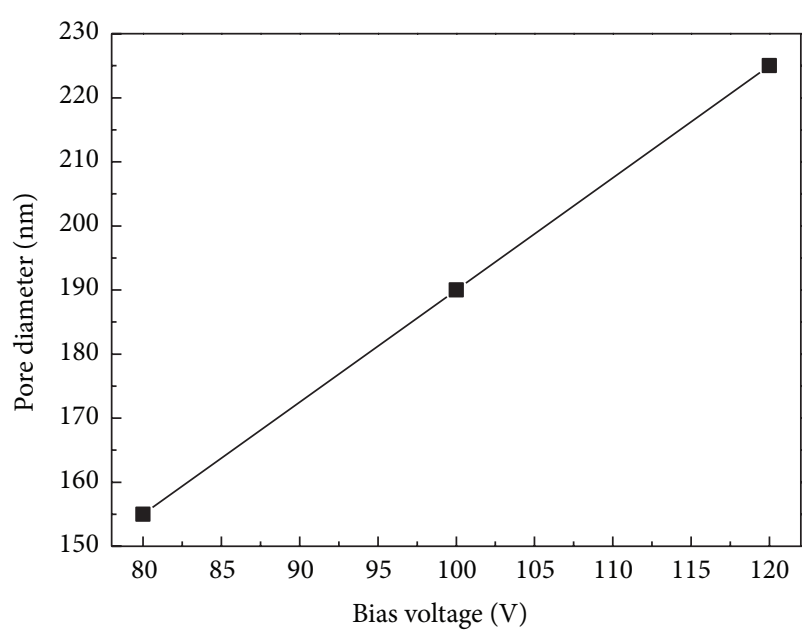

FIGURE 8: Diameter of pores in AAO/ITO/glass structure anodized at various bias voltages.

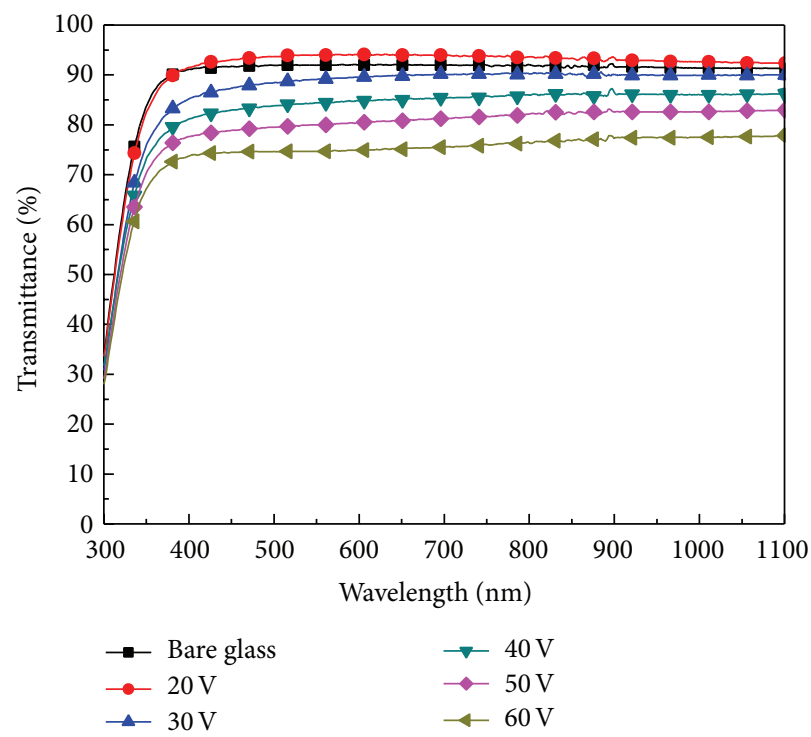

FIgURE 9: Optical transmittance of $\mathrm{AAO} /$ glass structure at bias voltages of $20 \mathrm{~V}, 30 \mathrm{~V}, 40 \mathrm{~V}, 50 \mathrm{~V}$, and $60 \mathrm{~V}$ after posttreatment annealing.

\section{Conclusion}

The study of porous anodic alumina on a $5 \mathrm{~cm} \times 5 \mathrm{~cm}$ ITO/glass substrate was demonstrated. The AAO/ITO/glass structure was used to solve the problem of unreacted $\mathrm{Al}$ inside the AAO template, which reduces the average transmittance in the AAO/glass structure. The enhancement of transmittance was observed by varying the diameter of pores and applying various biases. Pore-widening treatment and posttreatment annealing enhanced the optical transmittance of the AAO/ITO/glass structure in the near-infrared range. 


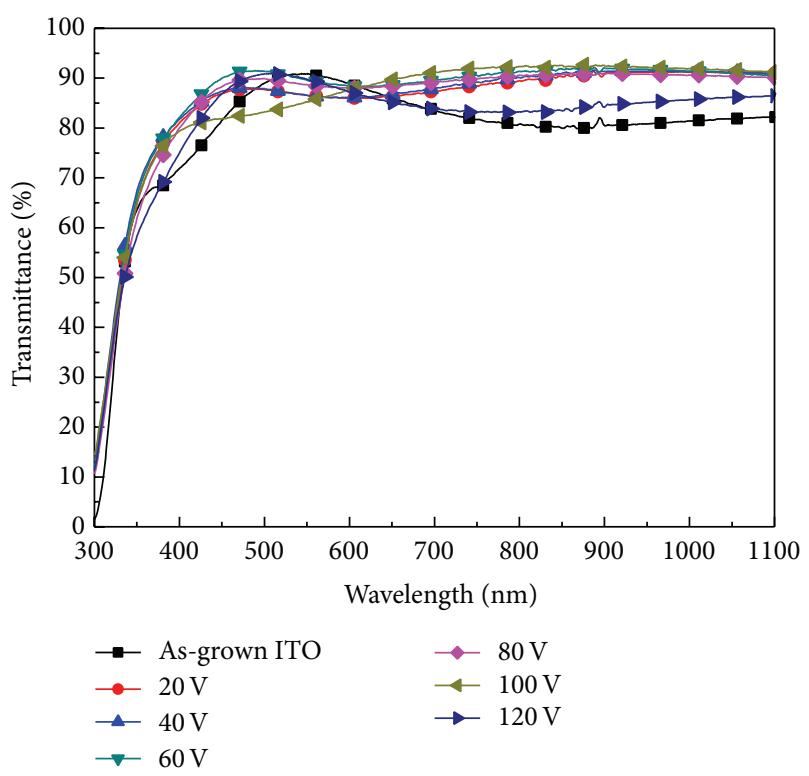

Figure 10: Optical transmittance of AAO/ITO/glass structure at bias voltages of $20 \mathrm{~V}, 40 \mathrm{~V}, 60 \mathrm{~V}, 80 \mathrm{~V}, 100 \mathrm{~V}$, and $120 \mathrm{~V}$ after posttreatment annealing.

The results thus obtained indicate that the AAO/ITO/glass structure has great potential for use in optoelectronic devices.

\section{Conflict of Interests}

The authors declare that they have no conflict of interests regarding the publication of this paper.

\section{Acknowledgments}

The authors would like to thank NexPower Technology Corporation for helpful discussions. They would also like to thank Mr. Yu-Yao Chen, the Chief Technology Officer of E-HENG Technology Co., Ltd., for assistance using the technical sputtering machinery. This work was also supported by the National Science Council of Taiwan under Contract no. NSC 97-2221-E-006-239-MY2.

\section{References}

[1] C. R. Martin, "Membrane-based synthesis of nanomaterials," Chemistry of Materials, vol. 8, no. 8, pp. 1739-1746, 1996.

[2] D. Routkevitch, A. A. Tager, J. Haruyama, D. Almawlawi, M. Moskovits, and J. M. Xu, "Nonlithographic nano-wire arrays: fabrication, physics, and device applications," IEEE Transactions on Electron Devices, vol. 43, no. 10, pp. 1646-1658, 1996.

[3] X. Wang and G.-R. Han, "Fabrication and characterization of anodic aluminum oxide template," Microelectronic Engineering, vol. 66, no. 1-4, pp. 166-170, 2003.

[4] S. Ono, M. Saito, M. Ishiguro, and H. Asoh, "Controlling factor of self-ordering of anodic porous alumina," Journal of the Electrochemical Society, vol. 151, no. 8, pp. 473-478, 2004.

[5] G. D. Sulka and K. G. Parkoła, "Temperature influence on well-ordered nanopore structures grown by anodization of aluminium in sulphuric acid," Electrochimica Acta, vol. 52, no. 5, pp. 1880-1888, 2007.

[6] A. L. Friedman, D. Brittain, and L. Menon, "Roles of $p \mathrm{H}$ and acid type in the anodic growth of porous alumina," Journal of Chemical Physics, vol. 127, no. 15, Article ID 154717, 2007.

[7] J. S. King, C. W. Neff, C. J. Summers et al., "High-filling-fraction inverted ZnS opals fabricated by atomic layer deposition," Applied Physics Letters, vol. 83, no. 13, pp. 2566-2568, 2003.

[8] N. W. Liu, A. Datta, C. Y. Liu, and Y. L. Wang, "High-speed focused-ion-beam patterning for guiding the growth of anodic alumina nanochannel arrays," Applied Physics Letters, vol. 82, no. 8, pp. 1281-1283, 2003.

[9] O. Kluth, B. Rech, L. Houben et al., "Texture etched $\mathrm{ZnO}: \mathrm{Al}$ coated glass substrates for silicon based thin film solar cells," Thin Solid Films, vol. 351, no. 1-2, pp. 247-253, 1999.

[10] Z. Fang, Y. Wang, X. Peng, X. Liu, and C. Zhen, "Structural and optical properties of $\mathrm{ZnO}$ films grown on the AAO templates," Materials Letters, vol. 57, no. 26-27, pp. 4187-4190, 2003.

[11] S. Z. Chu, K. Wada, S. Inoue, and S. Todoroki, "Formation and microstructures of anodic alumina films from aluminum sputtered on glass substrate," Journal of the Electrochemical Society, vol. 149, no. 7, pp. B321-B327, 2002.

[12] K. Nielsch, J. Choi, K. Schwirn, R. B. Wehrspohn, and U. Gösele, "Self-ordering regimes of porous alumina: the $10 \%$ porosity rule," Nano Letters, vol. 2, no. 7, 2002.

[13] C.-W. Wu, The effect of light current on amorphous thin film solar cell by the AAO/AZO front contact [M.S. thesis], National Cheng Kung University, 2010.

[14] K.-W. Lee, T.-H. Yang, W.-L. Lu, and M.-P. Houng, "Fabricating $20 \mathrm{~cm} \times 20 \mathrm{~cm}$ porous template using anodic aluminum oxide," Integrated Ferroelectrics, vol. 143, no. 1, pp. 47-57, 2013. 

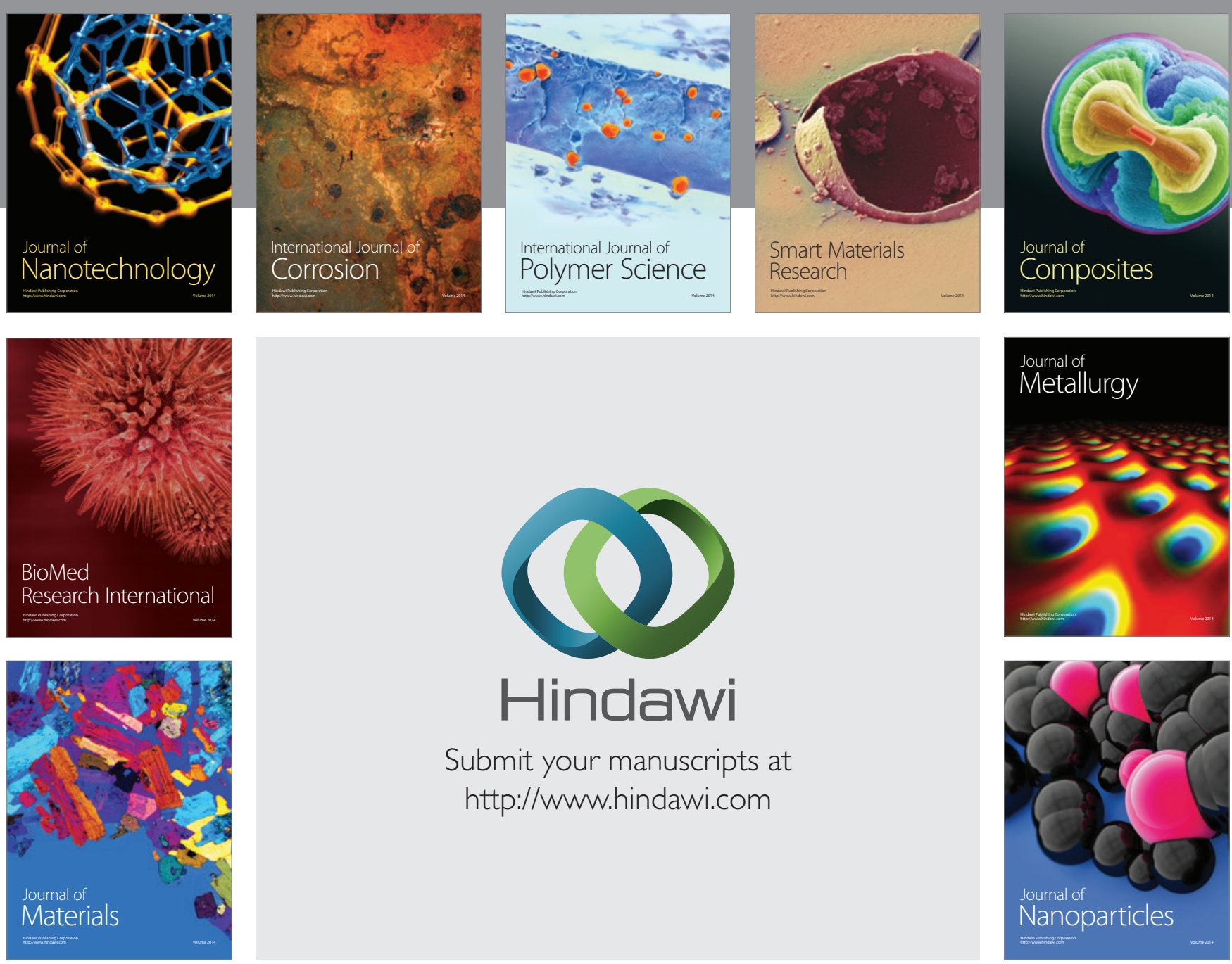

Submit your manuscripts at http://www.hindawi.com
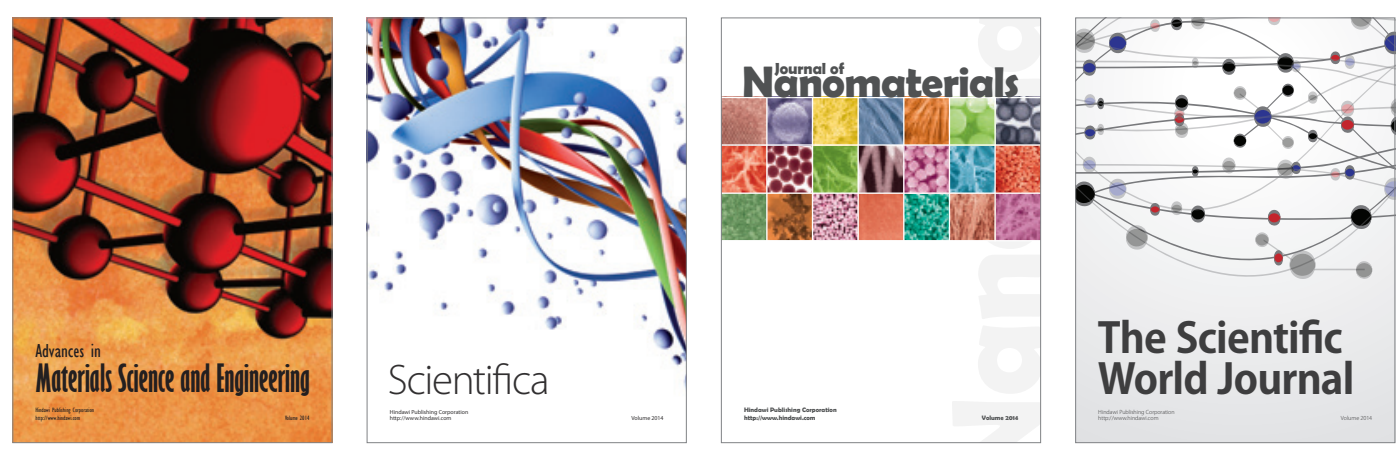

\section{The Scientific World Journal}
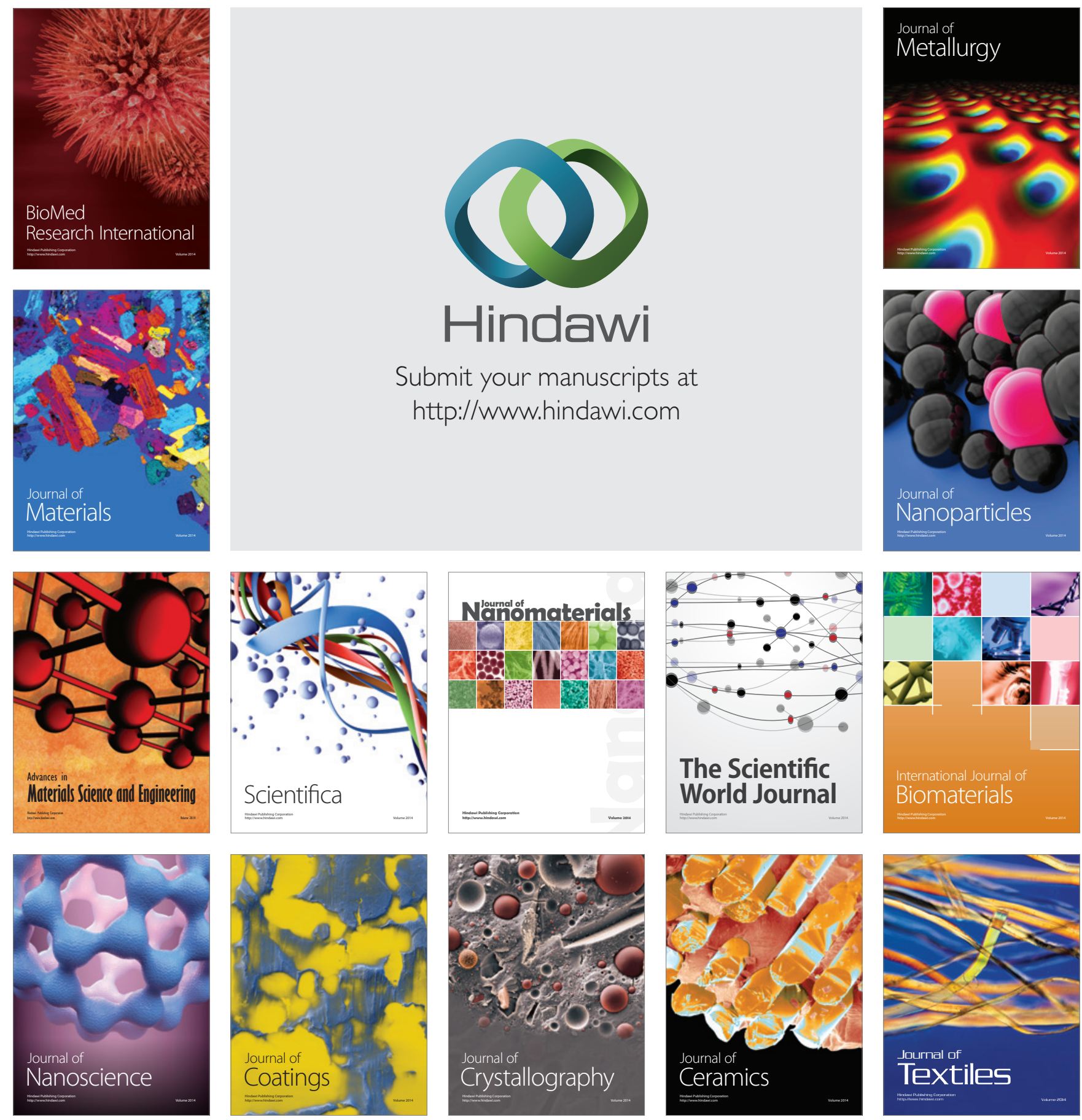